inclination of their spines the chests are very considerably deformed; the backs of each toward the front, or converging side, being perhaps flattened, and the ribs and scapulæ of the two other backs very prominent. The front of each of their chests is short in the vertical diameter, rounded and prominent. The heart of $M$. has been positively stated to be in the right side of the chest; but I could not feel persuaded of this, though there is evidently some displacement. This last may, perhaps, be owing to the distortion of the chest, though nothing of the kind is observed in $C$. Vesicular respiration was heard upon each side of the sternum; and the second sound of the heart was about as loud upon the right side of the chest as upon the left, but it was loudest over the sternum. The impulse could not be felt. Feeling this doubt as to the position of the organ, I suggested to Dr. Bowditch to visit the girls and to examine this point, and he writes to me as follows :dress.

"Millie was unwilling to remove her

"As far as I could examine her heart it seemed abont in the usual place, perbaps a little more towards the centre than usual, but I thought undoubtedly at the left of the sternum."

The pulse of $C$. was 72 , and that of $M$. rather less.

In the early part of the last century a very similar case occurred in Europe, and is well known to all who have paid any attention to the subject of monstrosities. I refer to the "Hungarian sisters," who lived to the age of 21 years; and, as they are so generally known by that name, it would seem proper to call the girls here described the " Carolina sisters."

\section{INSENSIBILITY TO PAIN FROM MENTAL} CAUSES.

By T. W. Fisher, M.D.

Tre question of the extent to which mental conditions, and especially insanity, can mask physical suffering, has been lately revived, during an investigation, by a committee of the Legislature, into the causes of the death of James Parks, at the Taunton Lunatic Hospital. This patient was arrested by the police of Cambridge while dashing about the streets, on horseback, under acute maniacal excitement. He was heard to ride into a fence, it being dark at the time, and was afterwards arrested, receiving several severe blows on the head. At the hospital, during a struggle with the at. tendants, whom he assaulted, he received further injury, and died the day after his admission. At the autopsy fourteen ribs were found broken, a part of them on each side of the chest anteriorly, and one lung was found punctured and collapsed. The evidence established, indirectly, the existence of injury to the chest before admission, a large ecchymosis having been noticed over the seat of fracture, on one side, but no expression of pain on the part of the patient led to an examination for deeper injuries. In the struggle at the hospital the lung was punctured, as evinced by a change in respiration with empbysema, and more ribs were probably broken.

The medical opinions concerning the mechanical disability arising from fractures of the ribs, the rate of progress in intiltration of tissues, and other incidental questions, were interesting, but need not be detailed here. In regard to the masking of pain by insanity, Dr. Morrill Wyman, of Cambridge, who saw Parks soon after the arrest, said he did not think his mental condition could have concealed the pain he must have felt from such numerovs fractures, and during such movements of the arms as were made in his presence.

Dr. Walker, of the Boston Lunatic Hospital, testified to the fact that insanity, in all its forms, may mask the pain from disease or injury of the most aggravated character, and gave instances occurring in his own experience. He did not consider it improbable that Parks's state of mind might have prevented any suffering from injuries as severe as those disclosed at the autopsy, and under such exertions as he is testified to have made. He further stated, that an insane man might complain of visible and prominent injuries, like those of the scalp, without calling attention to others more deeply seated and severe.

Dr. Fisher stated that immunity from pain, by reason of mental disease in most of its forms, was a well-known fact and matter of record. That cases of more extensive fractures of the ribs than the present, without evidence of pain, had been reported, and that this class of fractures was peculiarly liable to be concealed. That the movements testified to in this case, such as raising a window, were not the most difficult to perform under the circumstances, and called attention to the fact that after the injuries were known to exist, Parks raised himself in bed with his hands behind him-a movement involving the pectoral muscles. 
Dr. Shaw, of the Massachusetts General Hospital, related instances of patients who, in delirium, had thrown their wounded limbs against the wall, or jumped from bed, and walked on recent stumps. Also cases when, in the presence of other injuries, the patients not being insane, fractures of the ribs had been overlooked.

Dr. Choate, of the Taunton Hospital, presented records of parallel cases occurring in New York, when, under daily surgical supervision for weeks, including an operation in presence of a class of students, extensive fractures of the ribs were undiscovered.

The testimony of Dr. Tyler, of the McLean Asylum, was not heard by the writer, but is understood to have been of similar purport.

Probably no psychological fact is capable of such complete and startling illustration, as that of the endurance, or the loss of sense of pain, under certain mental conditions. From the time of Hippocrates, who first recorded insensibility to pain, as a symptom of insanity, to the present, medical literature contains frequent examples of it. The attempt has even been made to show the existence of this symptom in the majority of cases of insanity. It is a fact that such insensibility occurs in some degree in most forms of insanity-and from various causes, which it is important to analyze.

For instance, there may be actual paralysis of sensation, a condition of true anæsthesia; or, on the contrary, sensation may be perfect, and the seeming insensibility be due to a careful repression of the signs of pain for a specific purpose, as in some cases of hysterical paralysis. Between these extremes come varions degrees of indifference to pain, the result of mental pre-occupation in some morbid train of thought. There may also be the indifference of frenzy, the current of emotion admitting of no interruption, and the indifference of stupidity and dementia. The pain may be felt, but misinterpreted, by the diseased mind, and referred to some fanciful source, thereby being discredited.

In these and other ways, the exhibition of suffering among the insane is to a large extent prevented, and the utmost watchfulness is required on the part of medical attendants to discover the actual condition of parts and organs, of which, among the sane, the sense of pain is such a valuable index. Painful diseases, such as peritonitis and prostatic enlargement, may run Vor. III.-No. 23A their course with few of the rational signs. The pain from distention of the bladder often fails to give rise to any signs of suffering referable to that organ. Phthisis is quite uniformly a masked disease among the insane, being unaccompanied from the first to the last by pain, cough or sputa. The above remarks do not admit of a sweeping application, since many of the insane feel more acutely than others.

The most common cause of actual anæsthesia is general paralysis. In the carly stages of this disease, before the loss of motion is very observable, it may be well marked. It renders the patient regardless of exposure to extreme cold, to burns, injuries, and minor surgical operations. If under the influence of delusion at this time, self-mutilation may be deliberately inflicted. Pulling out of the intestines, gouging out the eyes, and sawing off the penis with a board, are a few of the eccentricities in which such patients may indulge.

A næsthesia may likewise exist in melencholia, being show $\mathrm{n}$ by indifference to cold, to the discomfort of lying naked on the floor, or of standing motionless from morning to night. Melancholiacs often resort to painful methods of suicide. Forbes Winslow relates a case of experimental suicide, in which the patient tried various plans, up to the point of unconsciousness, with the humane intention of recommending the best to his fellow sufferers! In dementia, the indifference to pain depends upon the extent of the mental obscuration. In mania, the condition bears less resemblance to anmethesia; or if it is of this nature, the state is transitory and fluctuating, according to the rate of the cerebral currents. Motory activity, however, is not always a safe index to the rate of psychical processes. The maniac may be outwardly calm, and perhaps coherent, at the moment when his mind is at its intensest point of activity. In this state there is no room for the consciousness of pain, and the patient may disregard the existence of severe injuries with a sang froid truly deceptive. I have seen such an one chew the burning ends of a card of matches with apparent relish.

This indifference to suffering is not, however, solely characteristic of insanity, since it is but an exaggeration of conditions not regarded as altogether abnormal. I need. only mention the convulsionaires of St. Medard, victims of one of those moral epidemics in which religious ecstasy produce an abolition of pain, with a wonderful exaltation of the power of endurance. The Book of 
Martyrs furnishes many examples of a'similar kind. A like condition obtains among the heathen and savages who use self-torture as a propitiatory exercise. There is a state of anæsthesia resulting from extreme peril, in some instances, of which Dr. Livingstone's account of his sensations while in the jaws of a lion is an instance. But war furnishes, on a large scale, the best examples of endurance and disregard of suffering.

The emotions developed during a battle are various. In a few constitutionally timid natures, they are of the most distressing character. Fear is imprinted on every feature, and every limb is a tell-tale. The term demoralized is strictly and scientifically applicable to such cases. In one instance under my own observation, an attack of mania was induced. A soldier, under unexpected fire for the first time, suddenly clubbed his musket and struck out furiously among his comrades, yelling all the while as if in the midst of the enemy. On being led out of the fight, the delirium subsided, leaving a condition of stupor which lasted several hours. He subsequently became a good soldier. In the same fight a young man became so exhilarated as to offer to stand guard all night, on account of his sleeplessness, the rest of the regiment being completely exhausted. He has since died of apoplexy.

In the mass, the excitement does not exceed the limits of self-control, but serves to keep each man up to his duty, and makes all more or less careless of danger, and indifferent to ordinary wounds. This is especially the case if the fight goes well. For instance; a soldier lies in an ambulance, with a bullet among the bones of the tarsus, shouting, "Dig away, Doctor, and damn the pain! we've licked 'em!" Or a delicate drummer boy, with a large flap of integument torn from his knee, requiring tedious dressing and many stitches, asks meanwhile for a pencil, to make notes in his diary of the occurrence! On the other hand, a fellow, with all the signs of cowardice, comes up with the right fore-finger shot off, and an empty gun-barrel. A selfinflicted wound is diagnosed, and amputation at the joint proceeds, arnid contortions and frantic exclamations of pain, while all around lie the severely wounded, with scarce a groan among them.

Such strong contrasts illustrate forcibly the influence of mental conditions upon sensibility to pain. It is a common error to enlargethe sphere of consciousness beyond its true limits. Consciousuess and cerebral activity are by no means co-extensive. Not only do organic processes and automatic actions go on unperceived, but unconscious trains of associated thought occupy the mind largely; awake as well as asleep. A certain degree of intensity in a nervous impulse seems necessary to a sense of consciousness, though of the laws which govern this matter we know little, and have slight control. Ideas and sensations rise into consciousness apparently at random, when not evoked by a direct effort of the will, or forced on the mind by their intensity. Pain is a sensation which in ordinary states has an element of intensity sufficient to excite the attention powerfully, but in abnormal conditions the brain seems under the absorbing control of centric agencies. Whatever these agencies are, whether changes in the circulation, or the cell nutrition, or the nervous currents, the results resemble, to some extent, artificial anæsthesia. Nature, however, more skilful than man, applies her anæsthetics so delicately as to produce more exact localizations of effect.

In the more permanent anæsthesia of insanity, we look for more visible and lasting changes of structure, such as atrophy of the nervous elements, abuormal growth of the connective tissue, or varicosity of the capillaries.

The subject, so liastily sketched, presents a field for more careful observation, and its phenomena should be fruitful of something besides incredulity or surprise.

\section{A COMBINED WIRE SPECULUM AND RE- TRACTOR.}

By Francis H. Brown, M.D., Boston.

A FEW weeks ago, I was asked by Dr. Waterman to assist him in a vaginal operation, which required the passage to be fully shown, and which promised to be, and, indeed, was quite protracted in its performance. I took occasion to suggest employing a simple wire speculum, which would answer the additional purpose of a retractor, in place of the Sims and Boston (Storer) specula and the copper spatulæ he was proposing to use. He carried out my idea by bending a stout wire on itself, and then shaping both folds nearly into the form of the letter $\mathbf{S}$; and thus got a very excellent and serviceable instrument.* Afterward I made, more carefully and after some experi-

* For sundry suggestions regarding this retractor, $I$ am indebted to Dr. Waterman, and a considerable part of the merit of the instrument-if merit exists-is due to that gentleman. 